\title{
Asymmetric Blepharospasm Treated with Botulinum Toxin-A: Case Report
}

\author{
(1) Gözde BARAN1, (i) Çiğdem DENİ2², ib Azize Esra GÜRSOY2, (1) Gülsen BABACAN YILDIZ22
}

${ }^{1}$ Şişli Hamidiye Etfal Training and Research Hospital, Clinic of Neurology, İstanbul, Turkey

${ }^{2}$ Bezmialem Vakıf University Faculty of Medicine, Department of Neurology, İstanbul, Turkey

\begin{abstract}
Benign essential blepharospasm (BEB) is a focal dystonia that causes involuntary occlusion of the eyelids as result of bilateral contraction of orbicularis oculi muscle. A 51-year-old female patient evaluated at the outpatient clinic with complaints of contraction and closure of the left eye for about 11 years and the same complaints of right eye for 10 years. Cranial magnetic resonance imaging was normal and blepharospasm was diagnosed based on the clinical and neurological evaluation. The patient underwent a botulinum toxin-A injection and was called for control 2 weeks later. BEB is a disease that seriously affects the quality of life of the patient, sometimes it can cause functional blindness. The time between diagnosis and treatment may be delayed in atypical cases. For this reason; differential diagnoses of atypical cases should be done well.
\end{abstract}

Keywords: Asymmetric, blepharospasm, focal, dystonia, botulinum toxin-A

\section{Introduction}

Benign essential blepharospasm (BEB) is the second most common focal dystonia after cervical dystonia which is caused by involuntary contraction of orbicularis oculi, procerus and neighbouring corrugator muscles $(1,2)$. The excessive activity of these muscles causes the eye to open and close too frequently or too vigorous to increase the blink frequency or cause functional blindness (2). Pathogenesis of the disease, as of all dystonias, is unknown; although it is thought to develop as a result of dysfunction in cortico-striato-thalamo-cortical circuits (3). Rarely, it may start unilaterally or asymmetrically, but almost always involves involuntary closure of both eyes (1). In patients who do not have typical onset or course, the diagnosis and treatment process may be delayed due to misdiagnosis. In this article; a patient with BEB who started unilaterally and still went on asimetrically for long years was reported with literature review.

\section{Case Report}

A 51-year-old female was admitted to the neurology outpatient clinic for contraction and closure of eyelids which started in the left side 11 years ago and spread to the right side 1 year later. The patient stated that especially in bright areas, the contraction and closure of eyelids increased significantly, and that from time to time the left eye was completely closed and therefore she had to open left eye with her hands, frequently. In neurologic examination, left eyelid was nearly completely closed and right eyelid was minimally closed. There was no contraction at the edges of the mouth. Especially while speaking, it was observed that the eyelids of the patient could remain open. The patient was trying to keep her eyelids open with her eyebrows raised. There was no history of illness, medication use or operation in her medical history. She had no history of disease in her family history. Routine blood tests (hemogram, biochemical tests, thyroid funtion tests) were normal. Cranial magnetic resonance 


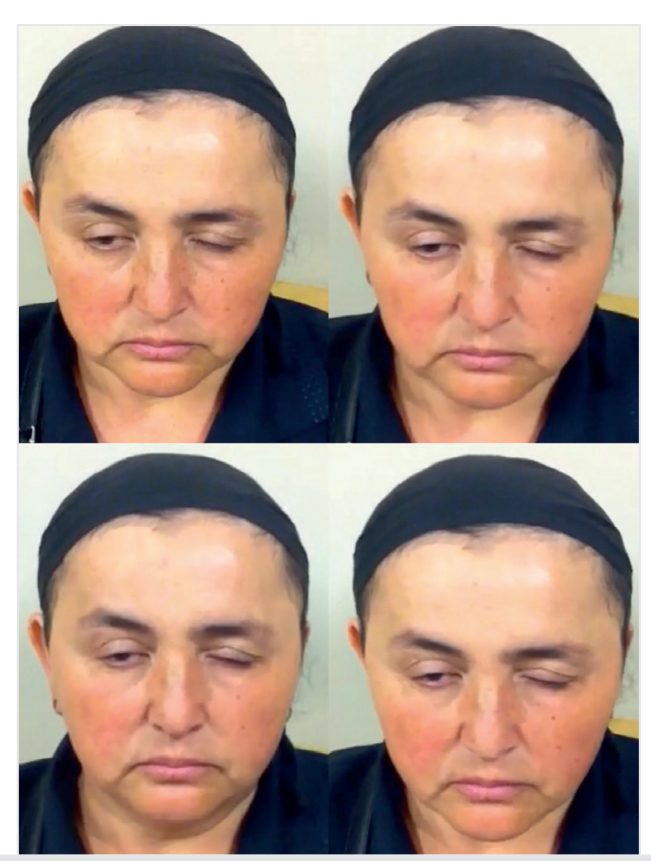

Figure 1. Before botulinum toxin-A injection

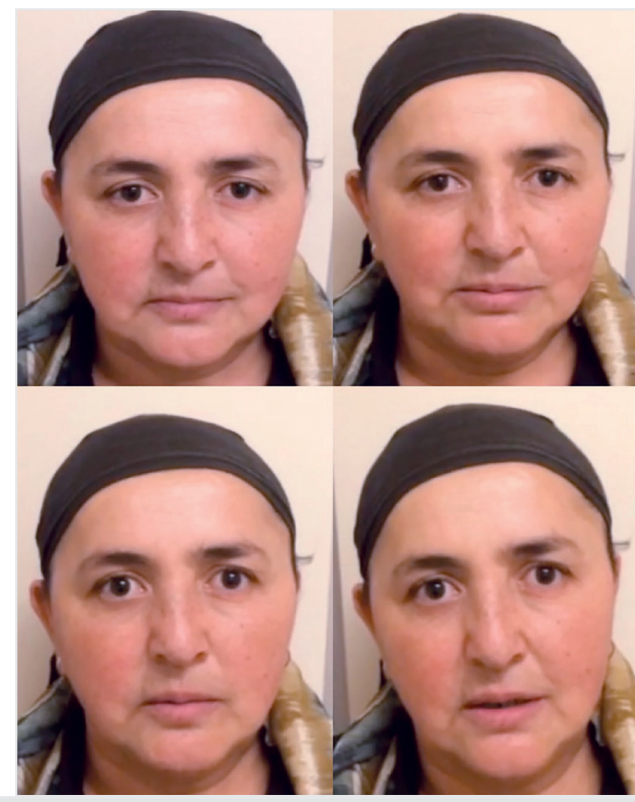

Figure 2. After botulinum toxin-A injection

and cranial magnetic resonance angiography imagings were normal. Diagnosis of blepharospasm was considered based on the anamnesis and neurologic examination findings and botulinum toxin-A injection was planned (Figure 1). Botulinum toxin $\left(\right.$ Botox $\left.^{\circ}\right)$ was diluted with $2 \mathrm{~mL} 0,9 \%$ sodium chloride and subcutaneously injected as 5 units into 5 different points in the pretarsal section of the orbicularis oculi muscle. Also 5 units were injected into the corrugator muscle. At 2 weeks follow-up, complaints of the patient improved almost completely (Figure 2).

Informed consent for using the patient's pictures was taken from the patient.

\section{Discussion}

$\mathrm{BEB}$ is a focal dystonia that causes the eyelids to involuntarily close as a result of two-sided contraction of the orbicularis oculi muscle (2). The main symptoms of BEB are involuntary contractions of eyelids and increased blink reflex resulting in chronic involuntary contractions that ultimately affect both eyes. BEB usually begins with the increase in the frequency of eye blinking. Spasm follows the increase in the frequency of eye blinking over time. Some patients develop functional blindness as a result of these spasms. A sensory trick in the form of stretching eyebrows and eyelids is often seen. Spasm starts bilateral in approximately $88 \%$ of cases $(4,5)$. Oftenly, diagnosis and pre-treatment processes can be prolonged. According to Jankovic and Orman (4), symptoms start 4-10 years before diagnosis in $50 \%$ of the patients and more than 10 years in $20 \%$ of the patients. We found out that our patient was followed up from an ophthalmology outpatient clinic for a while after the onset of the complaints and then from a neurology outpatient clinic with the diagnosis of hemifasial spasm because of the spasms being very asymmetrical. In about $78 \%$ of the patients with $\mathrm{BEB}$, which is a progressive disease, dystonia can be seen in the lower face or neck region (Meige syndrome, orofacial dystonia or oromandibular dystonia) or in other parts out of the facial nerve region (6). The complaints of our patient started unilaterally, and in a short period of time spread to the other side as reported in the literature, but the patient had always distinctly asymmetric course. Several oral medications were used to treat BEB. These include anticholinergics (trihexyphenidyl, benztropine), GABAergic drugs (clonazepam, baclofen), antidopaminergics (tetrabenazine) and mexiteline. Because of side effects and low efficacy in evidence-based studies, oral agents are often not preferred in clinical practice. Aproclonidine, an alpha-2-adrenergic agonist, produces a lid elevation by sympathetic stimulation of the Muller muscle, but its therapeutic use is limited due to tachyphylaxis (7-12). Chemodenervation with botulinum toxin injection is an effective first step treatment in BEB. There are two main serotypes of botulinum toxin commercially available: Botulinum toxin- $\mathrm{A}$ and Botulinum toxin- $\mathrm{B}$. Botulinum toxin- $\mathrm{A}$ is more commonly used and contains onabotulinum toxin-A (ONA), abobotulinum toxin- $\mathrm{A}(\mathrm{ABO})$ and incobotulinum toxin- $\mathrm{A}$ (INC) (13). In the 2016 update, "Report of the therapeutical and Technology Assessment Subcommittee of the American Academy of Neurology", ONA and INC was considered as evidence level $\mathrm{B}, \mathrm{ABO}$ was considered as evidence level $\mathrm{C}$ as treatment options (14). More than $90 \%$ of motor symptoms have been observed to improve after botulinum toxin treatment in BEB (15). Therefore, we preferred to use onabotulinum toxin $\left(B^{\circ}{ }^{\circ} x^{\circ}\right)$ in our patient. Spontaneous remission rates in BEB were reported in a wide range of $1.2-11.4 \%(16,17)$. In the first or second degree relatives of approximately one third of the patients, the presence of at least one of the disorders including BEB, Meige syndrome, Parkinson's disease, or essential tremor suggests that some patients have a genetic predisposition (5). However, most patients with BEB are sporadic and the causing gene has not been identified. A history of a movement disorder was not found in the first and second degree relatives of our patient. 
Some disorders should be considered in differential diagnosis of BEB. If contraction affects one side of the face, hemifacial spasm should be considered as diagnosis but it should be noted that BEB rarely presents unilateral initially. Hemifacial spasm remains unilateral in its course, but BEB always becomes bilateral although it can present unilateral initially (6). If spasm affects one group of fibers in the orbicularis oculi muscle, the diagnosis is probably ocular myokymia. If bilateral eyelid spasms are associated with twitching or spasms in one part of the face, the most accurate diagnosis is Meige syndrome or idiopathic cranial-cervical dystonia. Antidepressants, antihistaminics, sympathomimetics, dopamine blocking or stimulating drugs and decongestants should be investigated as possible triggers of BEB (6). Other diseases that need to be considered in differential diagnosis are apraxia of eyelid opening which is characterized by difficulty in voluntary opening of eyelid without spasm in the orbicularis oculi muscle, reflex blepharospasm and blepharitis $(6,18)$.

BEB is a disease that disrupts the quality of life of patients by even causing functional blindness. The time between diagnosis and initiation of treatment can be delayed, especially in patients with atypical onset course. Presenting with unilateral twitching of eyelids and continuing its course as significantly asymmetric, lack of symptoms in other parts of the face except eyelids, stretching eyebrows as a sensory trick and good response to botulinum toxin-A injection suggest a diagnosis of BEB. Therefore, it is important to note that in patients who do not have a typical onset or course, it may interfere with other diseases in the differential diagnosis.

\section{Ethics}

Informed Consent: Informed consent for using the patient's pictures was taken from the patient.

Peer-review: Externally peer-reviewed.

\section{Authorship Contributions}

Surgical and Medical Practices: G.B.Y., Concept: G.B.Y., A.E.B.G., Design: G.B.Y., A.E.B.G., Data Collection or Processing: G.B., Analysis or Interpretation: G.B., Ç.D., Literature Search: G.B., Ç.D., Writing: G.B.

Conflict of Interest: No conflict of interest was declared by the authors.

Financial Disclosure: The authors declared that this study received no financial support.

\section{References}

1. Jankovic J, Kenney C, Grafe S, Goertelmeyer R, Comes G. Relationship Between Various Clinical Outcome Assessments in Patients with Blepharospasm. Movement Disorders 2009;24:407-13.
2. Durmaz NF, Akbostancı CM. Primer Distoniler. In: Emre M, editor. Nöroloji Temel Kitabı. Ankara; 2013. p.857.

3. Hallett M. Blepharospasm: recent advances. Neurology 2002;59:1306-12.

4. Jankovic J, Orman J. Blepharospasm: demographic and clinical survey of 250 patients. Ann Ophthalmol 1984;16:371-6.

5. Malinovsky V. Benign essential blepharospasm. J Am Optom Assoc 1987;58:646-51.

6. Ben Simon GJ, McCann JD. Benign Essential Blepharospasm. Int Ophthalmol Clin 2005;112:49-75.

7. Vijayakumar DD. Treatment of blepharospasm with apraclonidine. J Neurol Sci 2017;372:57.

8. Gollomp SMS. Therapeutic trials in Meige syndrome. Adv Neurol 1983;37:207.

9. Nutt JGJ. Cranial dystonia: double-blind crossover study of anticholinergics. Neurology 1984;34:215.

10. Merikangas JRJ. Blepharospasm: successful treatment with clonazepam. Ann Neurol 1979;5:401.

11. Ohara SS. Mexiletine in the treatment of blepharospasm: experience with the first three patients. Mov Disord 1999;14:173.

12. Jankovic JJ. Treatment of hyperkinetic movement disorders with tetrabenazine: a double-blind crossover study. Ann Neurol 1982;11:41.

13. ARA B. Retrospective evaluation of the döşe equivalence of Botox $\left(^{(}\right)$ and Dysport $\left(^{\oplus}\right)$ in the management of blepharospasm and hemifacial spasm: a novel paradigm for a never ending story. Neurol Sci 2012;33:261.

14. DMD S. Practice guideline update summary: botulinum neurotoxin for the treatment of blepharospasm, cervical dystonia, adult spasticity, and headache: report of the Guideline Development Subcommittee of the American Academy of Neurology. Neurology 2016;86:1818.

15. Hanganu AA. Grey matter microstructural integrity alterations in blepharospasm are partially reversed by botulinum neurotoxin therapy. Public library of science. PLoS One 2016;11:e0168652.

16. Grandas F, Elston J, Quinn N, Marsden CD. Blepharospasm: a review of 264 patients. J Neurol Neurosurg Psychiatry 1988;51:767-72.

17. Castelbuono A, Miller NR. Spontaneous remission in patients with essential blepharospasm and Meige syndrome. Am J Ophthalmol 1998; 126:432-5.

18. Jinnah HA, Berardelli A, Comella C, Defazio G, Delong MR, Factor $S$, et al. Dystonia Coalition Investigators. The Focal Dystonias: current views and challenges for future. Mov Disord 2013;28:92643. 